\title{
A Gas-Powered, Patient-Responsive Automatic Resuscitator for Use in Acute Respiratory Failure: A Bench and Experimental Study
}

\author{
Annemijn H Jonkman, Bhushan H Katira, Annia Schreiber, Cong Lu, Doreen Engelberts, \\ Fernando Vieira, Alexandra Marquez, Arthur S Slutsky, Paul Dorian, and Laurent J Brochard
}

\begin{abstract}
BACKGROUND: During the COVID-19 pandemic, a need for innovative, inexpensive, and simple ventilator devices for mass use has emerged. The Oxylator (CPR Medical Devices, Markham, Ontario, Canada) is an FDA-approved, fist-size, portable ventilation device developed for out-of-hospital emergency ventilation. It has not been tested in conditions of severe lung injury or with added PEEP. We aimed to assess the performance and reliability of the device in simulated and experimental conditions of severe lung injury, and to derive monitoring methods to allow the delivery of safe, individualized ventilation during situations of surge. METHODS: We bench-tested the functioning of the device with an added PEEP valve extensively, mimicking adult patients with various respiratory mechanics during controlled ventilation, spontaneous breathing, and prolonged unstable conditions where mechanics or breathing effort was changed at every breath. The device was further tested on a porcine model (4 animals) after inducing lung injury, and these results were compared with conventional ventilation modes. RESULTS: The device was stable and predictable, delivering a constant flow $(30 \mathrm{~L} / \mathrm{min})$ and cycling automatically at the inspiratory pressure set (minimum of $20 \mathrm{~cm} \mathrm{H}_{2} \mathrm{O}$ ) above auto-PEEP. Changes in respiratory mechanics manifested as changes in respiratory timing, allowing prediction of tidal volumes from breathing frequency. Simulating lung injury resulted in relatively low tidal volumes $\left(330 \mathrm{~mL}\right.$ with compliance of $\left.20 \mathrm{~mL} / \mathrm{cm} \mathrm{H}_{2} \mathrm{O}\right)$. In the porcine model, arterial oxygenation, $\mathrm{CO}_{2}$, and $\mathrm{pH}$ were comparable to conventional modes of ventilation. CONCLUSIONS: The Oxylator is a simple device that delivered stable ventilation with tidal volumes within a clinically acceptable range in bench and porcine lung models with low compliance. External monitoring of respiratory timing is advisable, allowing tidal volume estimation and recognition of changes in respiratory mechanics. The device can be an efficient, low-cost, and practical rescue solution for providing short-term ventilatory support as a temporary bridge, but it requires a caregiver at the bedside. Key words: mechanical ventilation; pandemic; COVID-19; acute respiratory failure; rescue ventilation. [Respir Care 2021;66(3):366-377. (c) 2021 Daedalus Enterprises]
\end{abstract}

\section{Introduction}

The coronavirus (COVID-19) pandemic has highlighted challenges with access to and possible critical shortages of medical equipment in settings with overwhelming needs. ${ }^{1-3}$

\footnotetext{
Ms Jonkman, Mr Vieira, and Drs Schreiber, Lu, Slutsky, Dorian, and Brochard are affiliated with Keenan Research Centre, Li Ka Shing Knowledge Institute, St. Michael's Hospital, Toronto, Canada. Ms Jonkman, Dr Katira, Mr Vieira, and Drs Schreiber, Lu, Slutsky, and Brochard are affiliated with the Interdepartmental Division of Critical Care Medicine, University of Toronto, Toronto, Canada. Ms Jonkman is affiliated with the Department of Intensive Care Medicine, Amsterdam
}

Unexpected surges of patients with life-threatening respiratory illnesses motivated some centers to consider splitting ventilators between patients, ${ }^{4,5}$ ventilating patients outside of the ICU, and using ventilators not designed for ICUs. These approaches have major limitations, and the 


\section{Automatic Resuscitator for EMERgENCy Ventilation}

capabilities and potential complications of these unconventional methods are poorly understood. Substantial government funding has led to scaled-up production of ventilators

\section{See the Related Editorial on Page 533}

and a number of initiatives to design and build new, "simple" ventilators suitable for mass production in emergencies. ${ }^{6}$ Effective, inexpensive, and simple-to-use mechanical ventilators are needed to ventilate patients with COVID-19 at the onset of respiratory failure, in emergency rooms, outside of ICU settings, or during ICU stay and the prolonged recovery period. ${ }^{1-3,7,8}$ Such equipment may also be needed in future regional epidemic episodes or in under-resourced settings.

The Oxylator (CPR Medical Devices, Markham, Ontario, Canada), which has the Conformitè Europëenne mark and is FDA approved, is a fist-size, ultra-light, portable ventilation device developed for out-of-hospital use during resuscitation from cardiac arrest and emergency ventilation. ${ }^{9,10}$ It delivers patient-triggered or automated constant-flow, pressurecycled breaths. It can be used with a PEEP valve placed in series and requires minimal adjustments (adjustable set pressure above PEEP). Limitations include a complete lack of monitoring displays, and settings are restricted to the pressure limit. Although the device is used in different countries during prehospital emergencies, it is unclear whether its use could be extended to situations of severe lung injury, especially given its lack of monitoring. It has never been tested in conditions of severe lung injury, such as that seen in COVID-19-related ARDS, nor in an ICU setting. Provided that the ventilation delivered can be predicted, it could be a useful device in critical situations as a bridge treatment until an ICU ventilator is available, or in resource-deprived settings where mechanical ventilators are unavailable or impractical. We aimed to assess the ventilation delivered and its predictability in terms of volume and rate based on

Canada. Dr Dorian is affiliated with the Division of Cardiology, University of Toronto, Toronto, Canada.

Drs Dorian and Brochard are co-senior authors.

This work was supported in part by Toronto COVID-19 Action Fund from the University of Toronto and CIHR (FDN143285 and OV3170344). The Oxylator devices were provided free of charge by CPR Medical Devices; the company played no role in the design and conduct of the study.

Correspondence: Laurent J Brochard MD, Li Ka Shing Knowledge Institute, 209 Victoria St, Room 4-08, Toronto, ON, M5B 1T8 Canada. E-mail: laurent.brochard@unityhealth.to.

DOI: $10.4187 /$ respcare. 08296

\section{QUICK LOOK}

\section{Current knowledge}

During the COVID-19 pandemic, a need for innovative, inexpensive, and simple ventilator devices for mass use has emerged. The Oxylator is an FDA-approved, fistsize, portable ventilation device developed for out-ofhospital emergency ventilation. However, it has never been tested in conditions of severe lung injury or with an added PEEP valve.

\section{What this paper contributes to our knowledge}

In bench and porcine lung injury models, the Oxylator delivered stable ventilation with tidal volumes within a clinically acceptable range in lungs with low compliance. External monitoring of respiratory timing is advisable to allow bedside estimation of tidal volume and recognition of changes in respiratory mechanics. The device can be an efficient, low-cost, and practical rescue solution for providing short-term ventilatory support as a temporary bridge, but its use requires a caregiver to always be present.

pressure settings and respiratory mechanics, especially in simulated and experimental conditions of severe lung injury; and to derive bedside monitoring methods to allow the delivery of safe, individualized ventilation in situations of surge, such as during the COVID-19 pandemic.

\section{Methods}

We studied 6 individual Oxylator devices (4 EMX models, 2 HD models; weight $=0.25 \mathrm{~kg}$ ) in a bench simulation and an animal model of lung injury. Experiments were primarily conducted with the EMX model, which is most commonly used worldwide. The bench study was performed at St. Michael's Hospital, Toronto, Canada. Animal experiments were performed at The Hospital for Sick Children, Toronto, Canada.

\section{Working Principle}

The device (Fig. 1) can be connected to a tracheal tube, face mask, or supraglottic airway. Connected to a standard compressed air/oxygen tank or wall unit (50 psi), the device delivers a constant flow of $30 \mathrm{~L} / \mathrm{min}$ and is entirely mechanical, requiring no electricity. A breath is triggered when the airway pressure $\left(\mathrm{P}_{\mathrm{aw}}\right)$ at end-expiration drops below a fixed low pressure and no longer opposes the weight of a valve that is then magnetically pulled into the inspiration position. Inspiration continues until a user-adjustable pressure above PEEP is reached, which can be set 


\section{Automatic Resuscitator FOR EMERGENCy VeNTILATION}
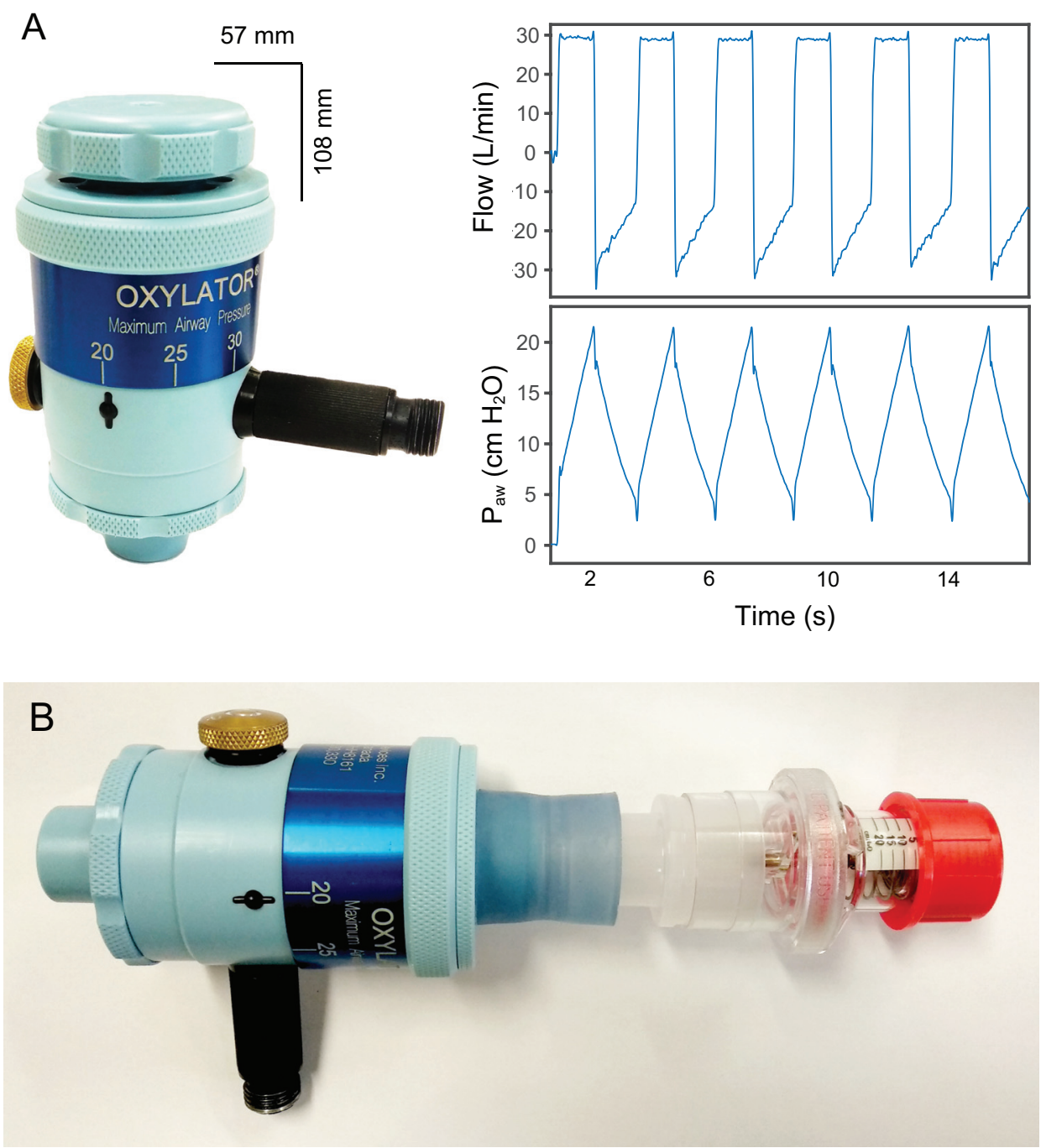

Fig. 1. A: The Oxylator EMX model $(0.25 \mathrm{~kg})$ and resulting flow and airway pressure $\left(P_{\text {aw }}\right)$ waveforms when no PEEP valve is attached. Connected to compressed gas (50 psi), the device delivers a constant flow of $30 \mathrm{~L} / \mathrm{min}$ without use of electricity. Inspiration, triggered by a nadir in $\mathrm{P}_{\mathrm{aw}}$, continues until a user-adjustable peak $\mathrm{P}_{\mathrm{aw}}$ is achieved $\left(20-45 \mathrm{~cm} \mathrm{H} \mathrm{H}_{2} \mathrm{O}\right.$ ). Expiration occurs passively (secondary to lung elastic recoil) until $\mathrm{P}_{\mathrm{aw}}$ declines to 2-4 $\mathrm{cm} \mathrm{H}_{2} \mathrm{O}$ (auto-PEEP generated by default), which triggers the next breath. Breathing frequency, inspiratory time, and tidal volume are not preset and are determined primarily by the patient's respiratory system compliance and airway resistance. The device itself has no monitoring available. B: The device with an AMBU PEEP valve attached.

at $20-45 \mathrm{~cm} \mathrm{H}_{2} \mathrm{O}$ on the EMX model and at $15-30 \mathrm{~cm} \mathrm{H}_{2} \mathrm{O}$ on the HD model. Inspiration then abruptly ceases, and expiration occurs passively (secondary to lung elastic recoil) until $\mathrm{P}_{\mathrm{aw}}$ declines to $2-4 \mathrm{~cm} \mathrm{H}_{2} \mathrm{O}$ (auto-PEEP generated by the device), which triggers the next breath. There is no capability for manual adjustment of breathing frequency (f), inspiratory time $\left(\mathrm{T}_{\mathrm{I}}\right)$, or tidal volume $\left(\mathrm{V}_{\mathrm{T}}\right)$ by the clinician. We reasoned that these parameters would be determined primarily by the patient's respiratory system compliance $\left(\mathrm{C}_{\mathrm{RS}}\right)$ and airway resistance, a characteristic that could be exploited for monitoring purposes. In addition to this automatic mode, breaths can be delivered manually by intermittently depressing the oxygen release button on the device. The device itself has no monitoring available; however, it does provide audible feedback (ie, cycling).

\section{Bench Study}

The device was tested with a spring-loaded PEEP valve (AMBU A/S, Denmark) (Fig. 1) on a 2-chamber Michigan test lung (Michigan Instruments, Grand Rapids, Michigan) to simulate various situations of severe lung injury; the device was also tested on an ASL 5000 (IngMar Medical, Pittsburgh, Pennsylvania) to simulate unstable situations and active assisted breathing. Because of the intrinsic expiratory resistance offered by the AMBU PEEP valve, we also 


\section{Automatic Resuscitator for EMERgENCy Ventilation}

performed experiments with a simple and less resistive PEEP generated with an underwater column. ${ }^{11}$

The Michigan test lung was used to simulate ARDS with various respiratory mechanics during controlled ventilation. The dial pressure of the device was set at $20 \mathrm{~cm} \mathrm{H}_{2} \mathrm{O}$ for the EMX model and at $15 \mathrm{~cm} \mathrm{H}_{2} \mathrm{O}$ for the HD model (minimum pressure possible). $\mathrm{C}_{\mathrm{RS}}$ was varied between 15 and 70 $\mathrm{mL} / \mathrm{cm} \mathrm{H}_{2} \mathrm{O}$, and airway resistance was varied between 10 and $30 \mathrm{~cm} \mathrm{H}_{2} \mathrm{O} / \mathrm{L} / \mathrm{s}$ to mimic lung injury and obstructive conditions. PEEP levels were set at 0,10 , and $20 \mathrm{~cm} \mathrm{H}_{2} \mathrm{O}$. This resulted in $>80$ combinations of $\mathrm{C}_{\mathrm{RS}}$, resistance, and PEEP levels that were tested, and 8-10 breaths per combination were recorded.

To test the reliability of the device, we simulated the following clinical problems of abrupt onset: (1) lung volume reduction due to complete airway obstruction: starting from a $\mathrm{C}_{\mathrm{RS}}$ of $50 \mathrm{~mL} / \mathrm{cm} \mathrm{H}_{2} \mathrm{O}$ and a resistance of $5 \mathrm{~cm}$ $\mathrm{H}_{2} \mathrm{O} / \mathrm{L} / \mathrm{s}$, one lung was clamped, followed by clamping of both lungs; (2) leak conditions were simulated by placing a connector with 2 small holes ( $2 \mathrm{~mm}$ in diameter) at the airway opening of the test lung, such that small leaks and large leaks were generated by opening one or both holes, respectively; and (3) pneumothorax: starting with normal $\mathrm{C}_{\mathrm{RS}}$ and resistance values, compliance of the affected lung was drastically reduced to simulate lung collapse. In addition, a heat and moisture exchanger (HME) filter was placed in-line for some measurements. To record $\mathrm{P}_{\mathrm{aw}}$ and air flow waveforms, a pneumotachograph was placed at the airway opening of the test lung and connected to a dedicated measurement setup (FluxMed GrT, MBMED, Buenos Aires, Argentina). Data were acquired at $256 \mathrm{~Hz}$. For some experiments, the pressure inside the test lung (ie, reflecting alveolar pressure) was recorded. The relationships between $V_{T}, f, T_{I}$, and $C_{R S}$ were analyzed by linear or nonlinear curve fitting, where appropriate (see statistical analysis).

The ASL 5000 was used first to evaluate the device during assisted ventilation. With combinations of a $\mathrm{C}_{\mathrm{RS}}$ of 30 and $50 \mathrm{~mL} / \mathrm{cm} \mathrm{H}_{2} \mathrm{O}$, resistance of 10 and $20 \mathrm{~cm} \mathrm{H}_{2} \mathrm{O} / \mathrm{L} / \mathrm{s}$, and a PEEP of 0 and $10 \mathrm{~cm} \mathrm{H}_{2} \mathrm{O}$, spontaneous breathing was simulated as an inspiratory patient effort (ie, muscle pressure) of 5, 15, and $25 \mathrm{~cm} \mathrm{H}_{2} \mathrm{O}$ to mimic low, moderate, and high breathing effort, respectively, with spontaneous $\mathrm{f}$ varying between 25 and 35 breaths/min and values of mechanics simulating what has been described for COVID$19 .^{12-14}$ Second, we tested the stability of the ventilation during prolonged periods $(>4 \mathrm{~h}$ ) of unstable respiratory mechanics to simulate an unstable patient. Mechanics (similar ranges of $C_{R S}$ and resistance values as used for the Michigan test lung experiments) and breathing effort (muscle pressure of 3-13 $\mathrm{cm} \mathrm{H}_{2} \mathrm{O}$ ) were randomly changed every breath. Waveforms were acquired on the ASL 5000 at a sampling frequency of $512 \mathrm{~Hz}$ and stored for offline analyses.

\section{Animal Model}

All experimental procedures were in compliance with the guidelines of the Canadian Committee for Animal Care and were conducted after approval by the Animal Care Committee of the Research Institute in The Hospital for Sick Children. Anesthetized pigs (4 animals, $35-40 \mathrm{~kg}$ ) were ventilated with an EMX model with dial pressure set at 20 or $25 \mathrm{~cm} \mathrm{H}_{2} \mathrm{O}$, using an inline $\mathrm{HME}$ filter and an AMBU PEEP valve. $\mathrm{F}_{\mathrm{IO}_{2}}$ was controlled with an external gas blender. The device was tested under 3 conditions for a 40-kg animal: normal lungs $\left(\mathrm{C}_{\mathrm{RS}}\right.$ 26-35 mL/cm $\left.\mathrm{H}_{2} \mathrm{O}\right)$, mild lung injury $\left(\mathrm{C}_{\mathrm{RS}} 15-19\right.$ $\left.\mathrm{mL} / \mathrm{cm} \mathrm{H}_{2} \mathrm{O}\right)$, and severe injury $\left(\mathrm{C}_{\mathrm{RS}} 9-11 \mathrm{~mL} / \mathrm{cm} \mathrm{H}_{2} \mathrm{O}\right)$. Lung injury was induced by a 2-hit method: lung lavage followed by high-stretch ventilation. ${ }^{15}$ Lung lavage was performed using warmed saline $0.9 \%$, in aliquots of $30 \mathrm{~mL} / \mathrm{kg}$ until $\mathrm{P}_{\mathrm{aO}_{2}}$ was $<100 \mathrm{~mm} \mathrm{Hg}$ for $10 \mathrm{~min}$. Pigs were then subjected to high-stretch ventilation, and $\mathrm{C}_{\mathrm{RS}}$ was measured every $15 \mathrm{~min}$. High-stretch ventilation was stopped upon reaching the desired target for a drop in compliance or in $\mathrm{P}_{\mathrm{aO}} / \mathrm{F}_{\mathrm{IO}_{2}}$. Mild and severe lung injury were defined according to the Berlin definition of ARDS. ${ }^{16}$

For the first 3 pigs, respiratory mechanics and gas exchange (sampled from the right carotid artery) measured during ventilation with the device were compared with conventional ventilation modes (pressure controlled and volume controlled ventilation) under conditions of normal lungs and after inducing lung injury (2 for mild injury, and 1 for severe injury). Two animals underwent conventional ventilation before changing the ventilator to the device, and one animal underwent ventilation with the device before conventional ventilation (Engström Carestation, GE, Boston, Massachusetts). The total experiment duration was 5-7 h. Because there are no standards for ventilation modes in pigs, we used pressure controlled and volume controlled modes with settings derived from previous experiments of lung injury in the laboratory to deliver lung-protective ventilation. ${ }^{15}$ PEEP and driving pressure delivered by the device (ie, peak $\mathrm{P}_{\mathrm{aw}}-\mathrm{PEEP}$ ) were matched with pressures obtained during conventional ventilation modes whenever possible (Table 1). A fourth pig was studied to assess the relationships between $V_{T}, f, T_{I}$, and $C_{R S}$ under conditions of normal lungs and after mild and severe lung injury. At each condition, additional changes in $C_{R S}$ were induced by performing stepwise lung recruitment maneuvers followed by both incremental and decremental PEEP conditions (from 0 to $25 \mathrm{~cm} \mathrm{H}_{2} \mathrm{O}$ and back to 0 $\mathrm{cm} \mathrm{H}_{2} \mathrm{O}$, in steps of $5 \mathrm{~cm} \mathrm{H}_{2} \mathrm{O}$ per 10-20 s). During all measurements, a pneumotachograph was placed at the endotracheal tube, and $\mathrm{P}_{\mathrm{aw}}$ and airway flow waveforms were acquired at $1 \mathrm{KHz}$ in LabChart (ADInstruments, Sydney, Australia) and stored for offline analysis. In 2 pigs, an electrical impedance tomography device (EIT; 







\section{Automatic Resuscitator for EMERgENCy Ventilation}

PulmoVista 500, Dräger, Lubeck, Germany) was attached via a 16-electrode belt for additional recording of lung impedance and ventilation distribution.

\section{Statistical Analysis}

Pressure and flow recordings were analyzed using software developed for Matlab R2019b (Mathworks, Natick, Massachusetts). From the flow tracings, peak inspiratory flow, $f, T_{I}$, expiratory time $\left(T_{E}\right), T_{I}$ to $T_{E}$ ratio (I-E ratio), and $\mathrm{V}_{\mathrm{T}}$ (ie, integral of inspiratory flow) were calculated. Peak $\mathrm{P}_{\mathrm{aw}}$, total PEEP, and driving pressure were derived from the pressure waveforms. To assess the possibility of predicting $\mathrm{V}_{\mathrm{T}}$ based on respiratory timing, the relationships between $V_{T}, f, T_{I}$, set pressure, and $C_{R S}$ were studied using linear or nonlinear (eg, power function) regression models, where appropriate.

Stability of the device during prolonged periods of unstable respiratory mechanics was inspected visually as well as quantified as the percentage of breaths for which $\mathrm{P}_{\mathrm{aw}}$ tracings remained within expected limits. To be considered stable, the device had to meet the following criteria: (1) for a device set pressure of $20 \mathrm{~cm} \mathrm{H}_{2} \mathrm{O}$, driving pressure had to be at least $15 \mathrm{~cm} \mathrm{H}_{2} \mathrm{O}$ (anticipating some resistive pressure to be subtracted); and (2) for a set PEEP of $x \mathrm{~cm} \mathrm{H}_{2} \mathrm{O}$, the resulting total PEEP had to be between $x-1$ and $x+5 \mathrm{~cm}$ $\mathrm{H}_{2} \mathrm{O}$ (considering additional auto-PEEP of the device).

For the animal experiments (ie, the first 3 pigs), respiratory mechanics and blood gas results for mechanical ventilation with the device and conventional modes, at different severities of induced lung injury, are presented as mean (95\% CI). Modes were compared by computing the distribution $(95 \% \mathrm{CI})$ for the difference of the means (at the .05 significance level). Data from the fourth pig were used to assess how predictable the device output (ie, the possibility to estimate $\mathrm{V}_{\mathrm{T}}$ ) was; the bench-derived model fit for predicting $\mathrm{V}_{\mathrm{T}}$ using $\mathrm{f}$ was applied to the pig data and the percentage of breaths that fell within the 95\% CI was calculated. From the EIT recordings, end-inspiratory lung impedance (EILI), end-expiratory lung impedance (EELI), and $\delta \mathrm{Z}$ (ie, changes in impedance during the respiratory cycle) were recorded at each PEEP level; as the device's driving pressure is constant, changes in $\delta \mathrm{Z}$ reflect changes in compliance. ${ }^{17}$

\section{Results}

\section{Bench Study}

Basic Settings. The device output varied as a function of the set pressure, the auto-PEEP generated by the device (2$4 \mathrm{~cm} \mathrm{H}_{2} \mathrm{O}$ ), and the respiratory mechanics. The flow was found to be constant at $28.7 \pm 1.7 \mathrm{~L} / \mathrm{min}$ across all conditions. A set pressure of $20 \mathrm{~cm} \mathrm{H}_{2} \mathrm{O}$ produced a driving pressure of 15-17 $\mathrm{cm} \mathrm{H}_{2} \mathrm{O}$ depending on the resistance and after subtracting resistive pressure and auto-PEEP of the device. Adding an HME filter reduced driving pressure by approximately $1 \mathrm{~cm} \mathrm{H}_{2} \mathrm{O}$, due to a small increase in resistance.

Because the flow is constant and the cycling is based on a preset pressure, the pressure limit is reached after $T_{I}$ depending on compliance. $T_{I}$ and $V_{T}$ vary together and depend on the set pressure and the compliance. Figure 2 shows the linear relationship between $T_{I}$ and $V_{T}$ using the EMX model with a set pressure of $20 \mathrm{~cm} \mathrm{H}_{2} \mathrm{O}$. The delivered $\mathrm{V}_{\mathrm{T}}$ was very close to expected based on the constant flow of $28.7 \pm 1.7 \mathrm{~L} / \mathrm{min}$ and the observed $\mathrm{T}_{\mathrm{I}}$, and therefore it was highly predictable. There was some variability in the I-E ratio depending on the respiratory mechanics, ranging from $1: 1$ to $1: 1.7$. Therefore, the relationship between $\mathrm{f}$ (assessed over a range of 5-35 breaths $/ \mathrm{min}$ ) and $\mathrm{V}_{\mathrm{T}}$ followed a power function, and $\mathrm{V}_{\mathrm{T}}$ could be reasonably well estimated: $\mathrm{V}_{\mathrm{T}}=10,530 \times \mathrm{f}^{-0.979}, \mathrm{R}^{2}=0.95$ $(P<.001)$. During simulated severe ARDS with a set $\mathrm{C}_{\mathrm{RS}}$ of $20 \mathrm{~mL} / \mathrm{cm} \mathrm{H}_{2} \mathrm{O}$, the EMX model at a set pressure of $20 \mathrm{~cm} \mathrm{H}_{2} \mathrm{O}$ resulted in $\mathrm{f}$ of 30 breaths/min (range, 2535 breaths $/ \mathrm{min}$ ) and $\mathrm{V}_{\mathrm{T}}$ of $330 \mathrm{~mL}$ (range, $300-360 \mathrm{~mL}$ ) (range due to variation in simulated resistance). With a $\mathrm{C}_{\mathrm{RS}}>50 \mathrm{~mL} / \mathrm{cm} \mathrm{H}_{2} \mathrm{O}$, the delivered $\mathrm{V}_{\mathrm{T}}$ was larger $(>800 \mathrm{~mL})$ and $\mathrm{f}$ was lower $(<14$ breaths/min). Because $\mathrm{V}_{\mathrm{T}}$ and $\mathrm{f}$ change reciprocally with changes in respiratory mechanics, minute ventilation remained fairly constant across all conditions at $10.4 \pm 0.3 \mathrm{~L} / \mathrm{min}$. For the HD model with a set pressure of $15 \mathrm{~cm} \mathrm{H}_{2} \mathrm{O}$, the driving pressure was $11-14 \mathrm{~cm} \mathrm{H}_{2} \mathrm{O}$. Accordingly, $\mathrm{V}_{\mathrm{T}}$ was within a clinically acceptable range $(<420 \mathrm{~mL})$ for $\mathrm{C}_{\mathrm{RS}}<30 \mathrm{~mL} / \mathrm{cm} \mathrm{H}_{2} \mathrm{O}$. With knowledge of the set pressure, both $\mathrm{C}_{\mathrm{RS}}$ and $\mathrm{V}_{\mathrm{T}}$ can thus be reasonably well predicted from breathing frequency.

Spontaneous Breathing. Figure 3 illustrates that spontaneous ventilation was possible: inspiration was almost always triggered when breathing effort resulted in a $\mathrm{P}_{\mathrm{aw}}$ drop below total PEEP. Due to the fixed flow, the pressure curve displayed a downward curvature, suggesting relative flow starvation, which, as expected, was more pronounced with increasing inspiratory breathing effort. Wasted efforts were only seen in simulated conditions of low inspiratory breathing effort $\left(5 \mathrm{~cm} \mathrm{H}_{2} \mathrm{O}\right)$ and high compliance $(50 \mathrm{~mL} / \mathrm{cm}$ $\mathrm{H}_{2} \mathrm{O}$ ).

Simulated Acute Problems. Simulated acute clinical problems were immediately noticed by abrupt audible changes in $\mathrm{f}$ (eg, inspiratory and expiratory cycling is easily audible); simulation of acute obstruction (eg, mucus plugging and atelectasis) resulted in a direct increase in $\mathrm{f}$ as a result of a compliance drop. In addition, the audible feedback from the device (eg, ultra-rapid cycling manifests as vibrations at high f) indicated a sudden 


\section{Automatic Resuscitator FOR EMERGENCy VeNTILATION}

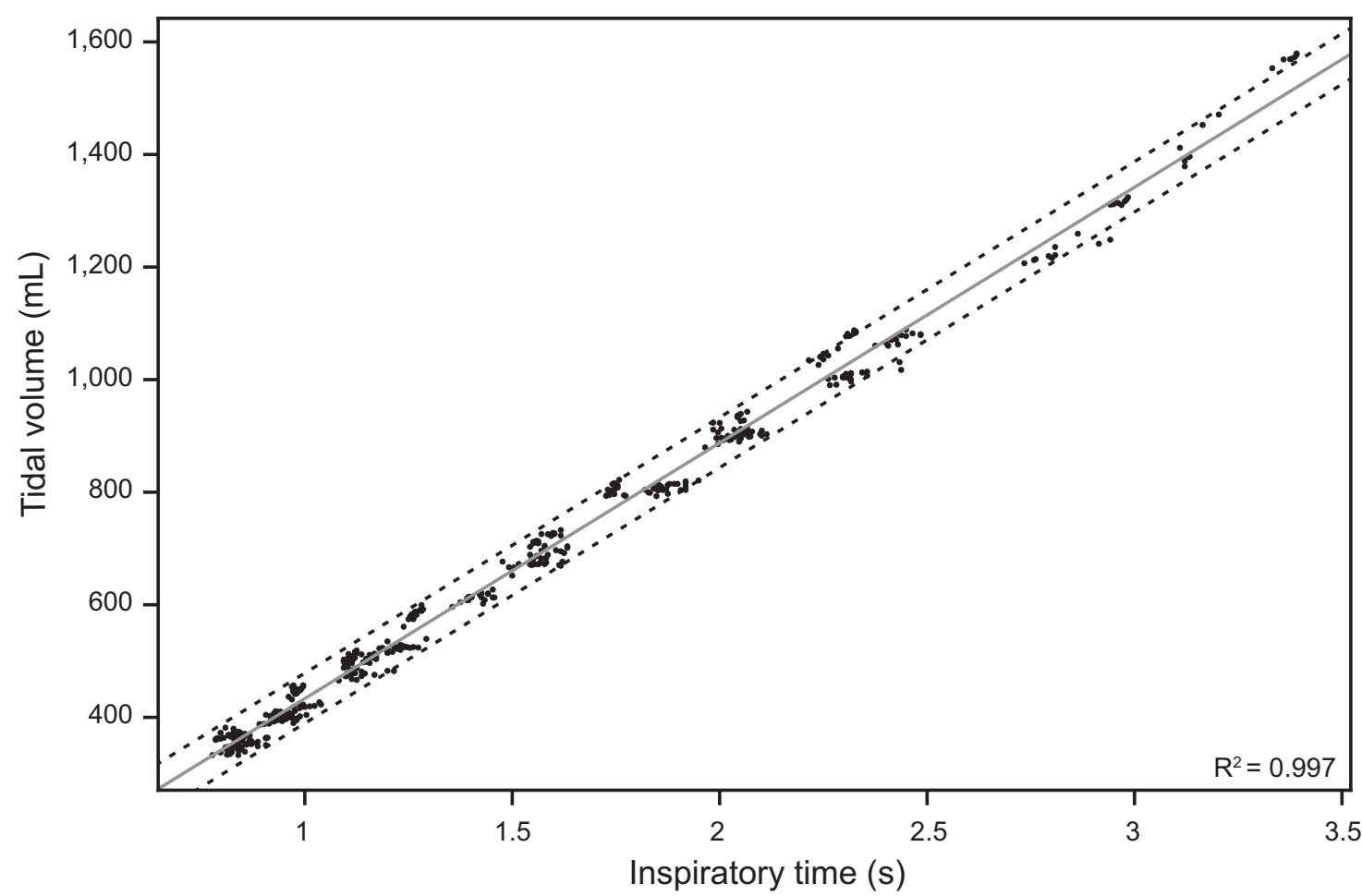

Fig. 2. Linear relationship between inspiratory time and tidal volume delivered with the device in a bench simulation with varied compliance and resistance $\left(\mathrm{R}^{2}=0.997, P<.001\right)$. Dashed lines represent $95 \% \mathrm{Cl}$. Delivered tidal volume based on inspiratory time was very close to expected based on the constant flow of $28.7 \pm 1.7 \mathrm{~L} / \mathrm{min}$ and the inspiratory time.
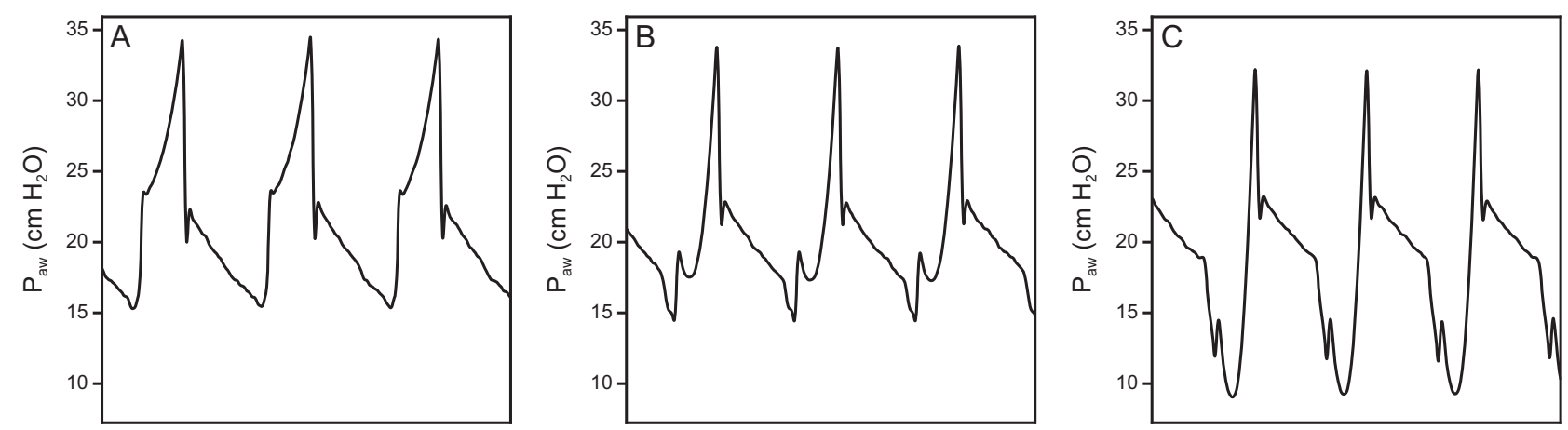

Fig. 3. Airway pressure $\left(\mathrm{P}_{\text {aw }}\right)$ waveforms for simulated active assisted breathing with the device under conditions with a compliance of 30 $\mathrm{mL} / \mathrm{cm} \mathrm{H} \mathrm{H}_{2} \mathrm{O}$ and resistance of $20 \mathrm{~cm} \mathrm{H}_{2} \mathrm{O} / \mathrm{L} / \mathrm{s}$. A PEEP of $12 \mathrm{~cm} \mathrm{H} \mathrm{H}_{2} \mathrm{O}$ was applied with the AMBU PEEP valve, resulting in a total PEEP of 15 $\mathrm{cm} \mathrm{H} \mathrm{H}_{2} \mathrm{O}$. Patient effort was simulated as a muscle pressure of (A) $5 \mathrm{~cm} \mathrm{H} \mathrm{H}_{2} \mathrm{O}$ (low effort), (B) $15 \mathrm{~cm} \mathrm{H}_{2} \mathrm{O}$ (moderate effort), and (C) $25 \mathrm{~cm} \mathrm{H} \mathrm{H}_{2} \mathrm{O}$ (high effort). Note that flow starvation is present with increases in muscle pressure, as evidenced by the downward curvature of the $\mathrm{P}_{\mathrm{aw}}$.

obstructed airway. Similarly, simulation of pneumothorax resulted in increased $\mathrm{f}$ due to decreases in compliance. Simulation of leaks resulted in prolonged $T_{I}$ or audible lack of cycling with significant leaks.

Unstable Conditions. Flow, pressure, and cycling were stable for a total of $8 \mathrm{~h}$ of study with different EMX models. A recording of at least $1 \mathrm{~h}$ was performed for each device. For a total of 11,295 simulated breaths in which $C_{R S}$, resistance, and muscle pressure were randomly varied at every breath, $\mathrm{P}_{\mathrm{aw}}$ tracings (ie, total PEEP and driving pressure values) were considered within expected limits for $99.6 \%$ of breaths. The output of the studied HD model was less stable; during a 1-h unstable respiratory mechanics simulation with low $\mathrm{C}_{\mathrm{RS}}(15-$ $30 \mathrm{~mL} / \mathrm{cm} \mathrm{H}_{2} \mathrm{O}$ ), normal resistance ( $\left.5-15 \mathrm{~cm} \mathrm{H}_{2} \mathrm{O} / \mathrm{L} / \mathrm{s}\right)$, and a PEEP of $10 \mathrm{~cm} \mathrm{H}_{2} \mathrm{O}$ (using the spring-loaded PEEP valve), $61.7 \%$ of breaths (611 of 991) had $\mathrm{P}_{\mathrm{aw}}$ values within the 

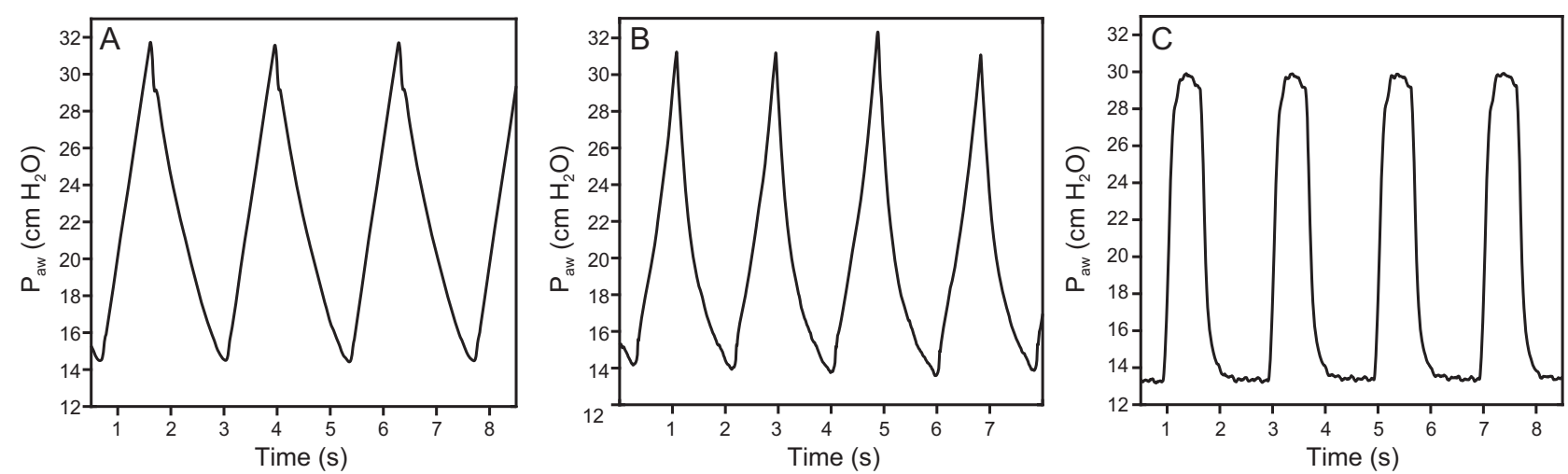

Fig. 4. Airway pressure $\left(\mathrm{P}_{\mathrm{aw}}\right)$ output of the device when tested $(\mathrm{A})$ on the bench and $(\mathrm{B})$ in pigs, and $(\mathrm{C})$ during pressure controlled ventilation in pigs, all during conditions with a respiratory system compliance of $20 \mathrm{~mL} / \mathrm{cm} \mathrm{H}_{2} \mathrm{O}$ and a PEEP of $10 \mathrm{~cm} \mathrm{H}_{2} \mathrm{O}$. Note that in pigs, the inspiratory time to expiratory time ratio is close to $1: 1$. Mean $\mathrm{P}_{\mathrm{aw}}$ during pressure controlled ventilation was matched with the device, resulting in a fairly similar total pressure delivered per breath (ie, the areas under the curves are relatively similar for ventilation with the device and pressure controlled ventilation in pigs).

expected range. Visual inspection of the waveforms revealed that this was related to premature triggering (ie, triggering at pressures $>4 \mathrm{~cm} \mathrm{H}_{2} \mathrm{O}$ above set PEEP) with rapid, small breaths.

Occasionally with the EMX model but more frequently with the HD model, premature triggering was observed when using the spring-loaded PEEP valve. It was never observed with the underwater column PEEP, nor when device was used without PEEP valve, which suggests that premature triggering was related to the way the spring-loaded PEEP valve worked and its interaction with the device. We could not identify specific respiratory mechanics settings related to the occurrence of this malfunction. Temporarily adjusting the PEEP (any change) or set pressure (by increasing it) on the device always quickly resolved the issue.

\section{Animal Model}

Device Output. Four EMX models were studied in animals with lung injury; for any given condition, all 4 showed similar ventilation output in terms of flow and pressure waveforms. In pigs, the I-E ratio was generally close to $1: 1$. As a result, the expiratory flow never reached a zero-flow condition before the start of a next inspiration. Figure 4 shows the $\mathrm{P}_{\mathrm{aw}}$ output of the device and pressure controlled ventilation with $\mathrm{C}_{\mathrm{RS}}$ of $20 \mathrm{~mL} / \mathrm{cm} \mathrm{H}_{2} \mathrm{O}$ and PEEP of $10 \mathrm{~cm} \mathrm{H}_{2} \mathrm{O}$, and the comparison with device output during the bench simulation with similar respiratory mechanics and set pressure. Under matched mean $\mathrm{P}_{\mathrm{aw}}$ conditions between pressure controlled ventilation and the device, the total pressure delivered per breath (ie, area under the curve) was fairly similar despite differences in $\mathrm{P}_{\mathrm{aw}}$ profile.

Gas Exchange. Oxygenation, $\mathrm{P}_{\mathrm{aCO}}$, and $\mathrm{pH}$ values obtained with the device and conventional modes of ventilation are shown in Table 1; values were comparable, with differences within acceptable clinical ranges among conditions and ventilator modes. For comparable PEEP and mean $\mathrm{P}_{\mathrm{aw}}$, the EMX device achieved good $\mathrm{V}_{\mathrm{T}}$ (normal lungs: $430-513 \mathrm{~mL}$; injured lungs: $250-344 \mathrm{~mL}$ ), minute ventilation (normal lungs: 11.2-12.5 L/min; injured lungs: 10.3-11.8 L/min), $\mathrm{P}_{\mathrm{aO}_{2}}$ (normal lungs: 142-236 mm Hg; injured lungs: 147$209 \mathrm{~mm} \mathrm{Hg}$ ), $\mathrm{P}_{\mathrm{aCO}_{2}}$ (normal lungs: $37-43 \mathrm{~mm} \mathrm{Hg}$; injured lungs: 52-89 mm Hg), and $\mathrm{P}_{\mathrm{aO}_{2}} / \mathrm{F}_{\mathrm{IO}_{2}}$ (normal lungs: 496511; injured lungs: 252-412); values represent $95 \% \mathrm{CI}$ of the mean; results for mild and severe lung injury were combined. At times, these values were better than those during conventional ventilation (Table 1).

Predicting $\mathbf{V}_{\mathbf{T}}$ From Respiratory Timing. In 1 pig, a total of 9 recruitment and de-recruitment PEEP trials were analyzed during ventilation with 4 different EMX devices under 3 conditions: normal lungs, mild induced lung injury, and severe induced lung injury. Data from the resulting 1,072 breaths with a wide range of $\mathrm{C}_{\mathrm{RS}}$ (range, $5.4-46.3 \mathrm{~mL} / \mathrm{cm}$ $\mathrm{H}_{2} \mathrm{O}$ ) were used to evaluate the relationship between $\mathrm{T}_{\mathrm{I}}$, f, and $\mathrm{V}_{\mathrm{T}}$. Similar to the bench study, predicting $\mathrm{V}_{\mathrm{T}}$ using observed $T_{I}$ and $f$ was possible. The equation for calculating $\mathrm{V}_{\mathrm{T}}$ from $\mathrm{T}_{\mathrm{I}}$ was $\mathrm{V}_{\mathrm{T}}=487.5 \times \mathrm{T}_{\mathrm{I}}-16.5, \mathrm{R}^{2}=0.99(P<$ .001), and the equation for calculating $\mathrm{V}_{\mathrm{T}}$ from $\mathrm{f}$ was $\mathrm{V}_{\mathrm{T}}=$ $11,010 \times \mathrm{f}^{-0.989}, \mathrm{R}^{2}=0.94(P<.001)$. We then assessed the accuracy of the bench-derived formula for calculating $\mathrm{V}_{\mathrm{T}}$ based on $\mathrm{f}$ compared to in vivo measured values. As shown in Figure 5, 84\% of the breaths fell within the 95\% CI limits of the bench formula; on average, the measured $\mathrm{V}_{\mathrm{T}}$ was $2.0 \pm 34.5 \mathrm{~mL}$ higher than the predicted $\mathrm{V}_{\mathrm{T}}$.

PEEP Titration. A decremental PEEP trial resulted in a $\mathrm{U}$-shaped response curve for $\mathrm{f}$, reflecting inverse compliance changes (Fig. 6). Starting from a high PEEP, 


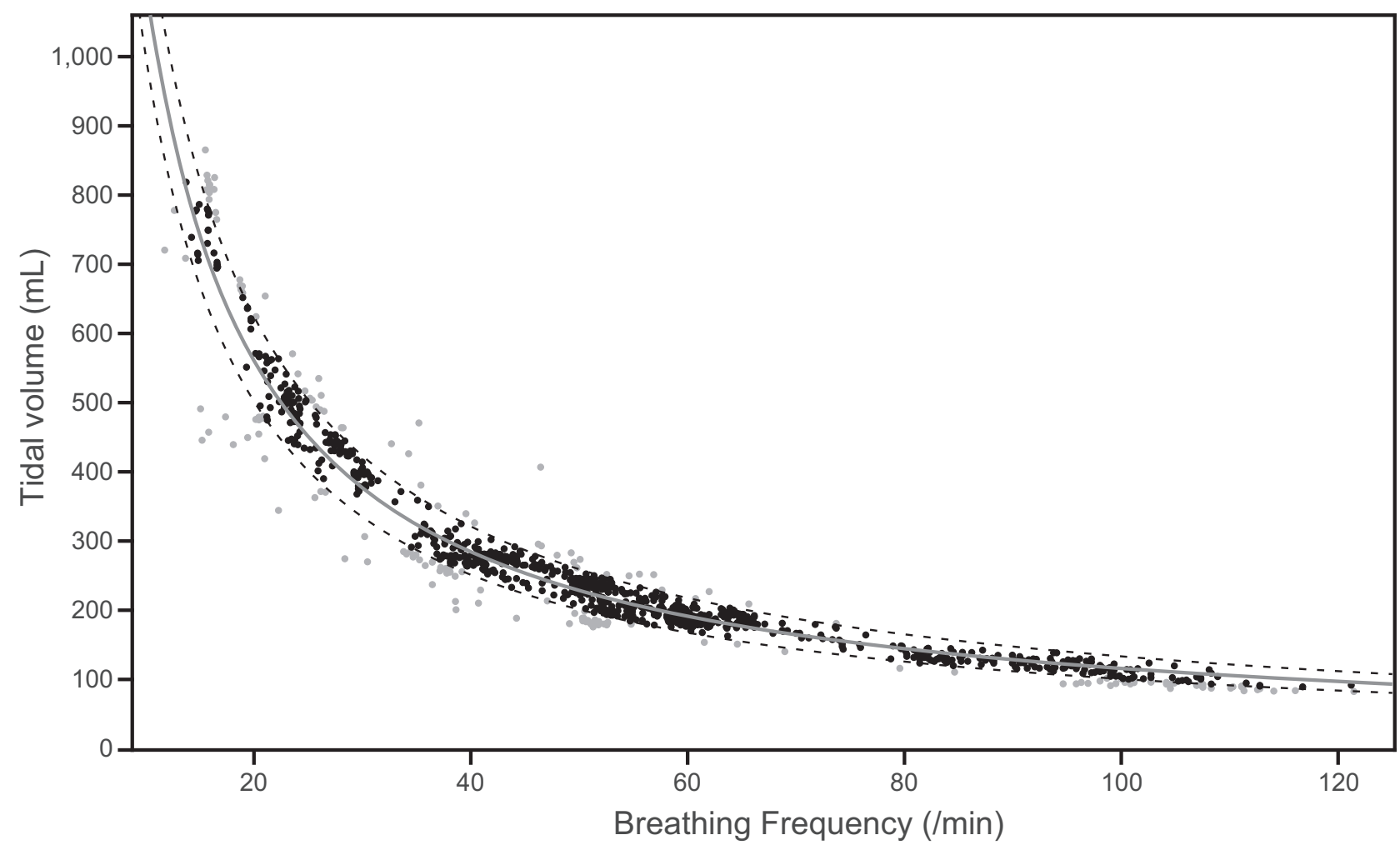

Fig. 5. Breathing frequency and tidal volume data from pigs with normal lungs and after inducing mild and severe lung injury. Additional changes in respiratory mechanics were obtained by performing PEEP recruitment maneuvers. The predictivity of the bench-derived formula for calculating tidal volume based on breathing frequency was tested by applying this formula to the pig data. As a result, $84 \%$ of the breaths (black dots) fell within the $95 \% \mathrm{Cl}$ limits of the bench formula; on average, the measured tidal volume was $2.0 \pm 34.5 \mathrm{~mL}$ higher than the predicted tidal volume.

compliance increased and $f$ decreased until a nadir of $f$ was reached; a further reduction in PEEP resulted in increased $\mathrm{f}$ due to the lower compliance induced by alveolar collapse. Therefore, the lowest $\mathrm{f}$ corresponded to the highest $\mathrm{C}_{\mathrm{RS}}$. Simultaneously recorded EIT data showed an inverse U-shaped pattern in $\delta \mathrm{Z}$ (Fig. 6); because the driving pressure was constant, the highest $\delta \mathrm{Z}$ corresponded to the highest $C_{R S}$, which coincided with the lowest $\mathrm{f}$. Using the hysteresis behavior method, we confirmed that this PEEP level corresponded to the highest compliance (ie, highest slope of the pressure-impedance curve); at the same PEEP level, the ventilation distribution was uniform between ventral and dorsal regions (Fig. 6).

\section{Discussion}

In the era of the COVID-19 pandemic and in preparation for the next pandemic, we need simple, efficient, and safe ventilation devices to meet the unprecedented ventilator demands of patients, and to cope with extraordinary logistical challenges. Our evaluation of the Oxylator yielded 4 notable results. First, for severe lung injury (low compliance), the device offers simplicity, electricity independence, and portability, and it delivers a $V_{T}$ within a clinically acceptable range at a relatively high $\mathrm{f}$. In normal lungs, $\mathrm{V}_{\mathrm{T}}$ will be larger. ${ }^{18}$ This makes the device especially suitable for respiratory systems with low compliance and short time constants. Second, the inability to adjust ventilator parameters other than the dial pressure makes controlling ventilation challenging; however, due to the predictable output and with monitoring of respiratory timing (via an external monitoring device or audible feedback), the user can calculate $C_{R S}$ and $V_{T}$ very precisely from $T_{I}$ and with reasonable accuracy from the $\mathrm{f}$ (given variations in the I-E ratio). Monitoring of respiratory timing is advisable because it could also help in recognizing acute clinical problems at the bedside. Third, the response curve in $\mathrm{f}$ during a decremental PEEP trial confirms the dependence of $f$ on $C_{R S}$ and could help the clinician to adjust the PEEP level. Finally, gas exchange in an animal model of lung injury was similar to conventional ventilation from a standard mechanical ventilator, using currently recommended pressure or volume-prioritized ventilation settings.

\section{Device Performance}

The ongoing pandemic has put a burden on critical care resources, especially mechanical ventilators. While modern 


\section{Automatic Resuscitator FOR EMERGENCy VeNTILATION}
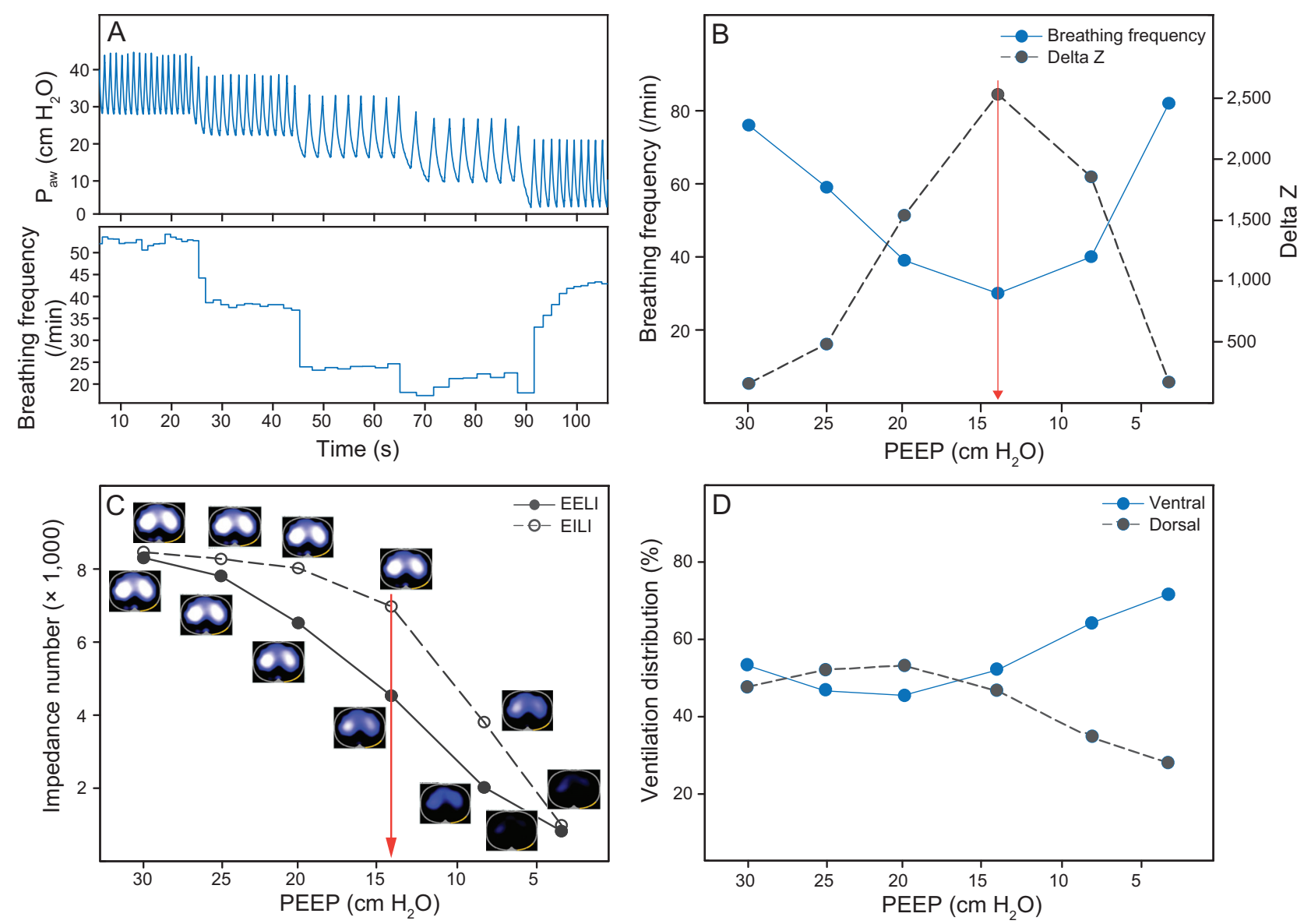

Fig. 6. After lung injury, decremental PEEP steps were conducted while using the Oxylator EMX device. (A) $P_{\text {aw }}$ and breathing frequency. As the applied PEEP was decreased from $25 \mathrm{~cm} \mathrm{H}_{2} \mathrm{O}$ to $0 \mathrm{~cm} \mathrm{H}_{2} \mathrm{O}$, the measured PEEP decreased from $30 \mathrm{~cm} \mathrm{H}_{2} \mathrm{O}$ to $3 \mathrm{~cm} \mathrm{H} \mathrm{H}_{2} \mathrm{O}$. Breathing frequency follows a U-shaped response curve with decreasing PEEP. (B) Data from a different pig while performing a decremental PEEP trial. In addition to the U-shaped response curve seen in breathing frequency, a reverse pattern is seen with $\delta$ Z measured with EIT. Because the driving pressure is constant, highest $\delta$ Z corresponds to best lung compliance, which in turn corresponds to lowest breathing frequency. (C) Lung impedance numbers at inspiration and expiration during the decremental PEEP steps along with corresponding EIT images in the same pig as in (B). The best compliance is in the middle steeper portion of the curve and corresponds to the best PEEP in (B), which is at $14 \mathrm{~cm} \mathrm{H}_{2} \mathrm{O}$. (D) Ventilation distribution for the dorsal and ventral lung regions, showing a uniform distribution at this best PEEP level. At lower PEEP levels, there is a discrepancy in ventilation distribution between ventral and dorsal lung regions, due to alveolar collapse occurring in the dorsal lungs. The uniform ventilation distribution at higher PEEP levels $\left(>14 \mathrm{~cm} \mathrm{H}_{2} \mathrm{O}\right)$ is the result of hyperinflation as shown in $(\mathrm{B})$ and $(\mathrm{C})$. $\mathrm{P}_{\text {aw }}=$ airway pressure; $\mathrm{EIT}=$ electrical impedance tomography; $\mathrm{EELI}=$ end-expiratory lung impedance; $\mathrm{EILI}=$ end-inspiratory lung impedance; $\delta \mathrm{Z}=\delta$ impedance.

ICU ventilators are sophisticated and reliable and provide extensive patient monitoring, they are expensive, making stockpiling of these ventilators cost-prohibitive. ICU ventilators are complex devices requiring extensive training for safe use and maintenance, and they require sources of electrical power, air, and oxygen pressure. They are not portable, and they require extensive quality control (especially if produced in non-standard conditions) and a reliable supply of disposable equipment. ${ }^{7,19}$ Ultra-simple and user-friendly, durable, portable, and low-cost ventilation solutions are therefore potentially important. ${ }^{1-3,7}$ The Oxylator could meet these requirements. It is currently used worldwide in prehospital settings during rescue situations such as after cardiac arrest or severe trauma. ${ }^{9,10,18}$ However, the device could be recommended for use in acutely ill patients with lung injury if safe, effective, and individualized ventilation can be achieved to deliver protective ventilation. Over a wide range of respiratory mechanics conditions, we demonstrated stable device output, successful delivery of PEEP, and protective $\mathrm{V}_{\mathrm{T}}$ in mild to severe lung injury, but, paradoxically, less in conditions of normal compliance, at least using the lowest pressure of the EMX model. Furthermore, short-term use of the EMX model resulted in ventilation and gas exchange comparable to conventional ventilation modes. This suggests that the device could be a relatively safe and efficient solution for shortterm rescue ventilation. 


\section{Automatic Resuscitator for EMERgENCy Ventilation}

\section{Breathing Frequency as Minimal Monitoring}

In contrast to conventional ventilation modes, the pressure cycling mechanism makes the $\mathrm{V}_{\mathrm{T}}$ delivered by the Oxylator directly dependent on the patient's respiratory mechanics. Because the device lacks monitoring displays, challenges arise and monitoring would be necessary to avoid excessive or insufficient $\mathrm{V}_{\mathrm{T}}$. Our results indicate that bedside estimation of $\mathrm{V}_{\mathrm{T}}$ is possible based on respiratory timing. Changes in $f$ could predict $V_{T}$ using a benchderived formula that was validated in an animal model over a large range of respiratory mechanics conditions, showing clinically acceptable variability in predicted $\mathrm{V}_{\mathrm{T}}$. This formula could be incorporated into an online calculator. In addition, monitoring $f$ allows recognition of changes in respiratory mechanics due to abrupt clinical problems (eg, acute obstruction, leaks) or disease progression. Furthermore, we suggest a method for setting PEEP at the bedside based on the $\mathrm{f}$ response to changes in compliance during a decremental PEEP trial. Indeed, the PEEP level based on this response corresponded to the PEEP related to the best EIT-derived compliance, as confirmed with lung impedance EIT data at this pressure level and uniform ventilation distribution. Although $\mathrm{f}$ could be monitored via the audible feedback of the device, this requires a caregiver to be present to listen carefully to the device's cycling. External devices such as a pulse oximeter, end-tidal $\mathrm{CO}_{2}$ monitor, or portable gas flow analyzer placed in series with the device would therefore be recommended.

\section{Limitations and Future Work}

Some limitations regarding the use of the device should be addressed. First, without an external blender, the gas is pure oxygen, which limits the duration of use. However, an air/oxygen blender could be added to control $\mathrm{F}_{\mathrm{IO}_{2}}$ delivery, although this may affect portability of the device and increase cost. Second, the minimum driving pressure of the EMX model limits its use in lungs with normal compliance. In these patients, excessive $V_{T}$ can be prevented when using the device in manual mode; however, this method requires a clinician to operate the device. Although lower driving pressures can be achieved with the HD model, fewer devices of this model are available worldwide compared to the EMX model $(>20,000$ devices have been sold). It should also be noted that, according to its intended use as an automatic resuscitator, the device should not be used unattended. Third, the use of a spring-loaded PEEP valve occasionally resulted in device malfunction, which manifested as premature triggering with high $\mathrm{f}$. This problem never occurred with non-resistive underwater PEEP generation. When this problem occurred, it was always easily resolved quickly by temporarily changing the PEEP level or the set pressure of the device; recognizing this problem requires monitoring of f. Last, spontaneous breathing is possible when using the device with added PEEP; however, due to the fixed flow, this may become uncomfortable if high respiratory efforts are allowed. Use without a PEEP valve (eg, during noninvasive application when connected to a face mask) allows ambient air to be inhaled when patient effort is high, but this should be used with caution and when PEEP is not necessary. Addressing these technical limitations in a next-generation model would enhance future clinical implementation. In addition, before widespread use of the device, its reliability and safe patient monitoring should be verified in a clinical setting of severe lung injury.

\section{Conclusions}

In bench and porcine models of severe lung injury, the Oxylator is a simple automated resuscitator delivering stable ventilation with $\mathrm{V}_{\mathrm{T}}$ within a clinically acceptable range in low compliance lungs. External monitoring of respiratory timing is advisable and allows estimation of the delivered $\mathrm{V}_{\mathrm{T}}$, could guide setting PEEP, and helps with recognizing sudden changes in respiratory mechanics due to clinical problems or disease progression. In resource-constrained settings such as those seen during the coronavirus pandemic or in environments with limited equipment, the Oxylator can be a low-cost practical rescue solution for providing short-term ventilatory support as a temporary bridge until an ICU ventilator becomes available.

\section{REFERENCES}

1. Emanuel EJ, Persad G, Upshur R, Beatriz T, Parker M, Glickman A, et al. Fair allocation of scarce medical resources in the time of COVID-19. N Engl J Med 2020;382(21):2049-2055.

2. Ranney ML, Griffeth V, Jha AK. Critical supply shortages - the need for ventilators and personal protective equipment during the COVID19 pandemic. N Engl J Med 2020;382(18):e41.

3. Grasselli G, Pesenti A, Cecconi M. Critical care utilization for the COVID-19 outbreak in Lombardy, Italy: early experience and forecast during an emergency response. JAMA 2020;323(16):1545.

4. Clarke AL, Stephens AF, Liao S, Byrne TJ, Gregory SD. Coping with COVID-19: ventilator splitting with differential driving pressures using standard hospital equipment. Anaesthesia 2020;75(7):872-880.

5. Han JS, Mashari A, Singh D, Dianti J, Goligher E, Long M, et al. Personalized ventilation to multiple patients using a single ventilator: description and proof of concept. Crit Care Explor 2020;2(5):e0118.

6. Garmendia O, Rodríguez-Lazaro MA, Otero J, Phan P, Stoyanova A, Dinh-Xuan AT, et al. Low-cost, easy-to-build non-invasive pressure support ventilator for under-resourced regions: open source hardware description, performance and feasibility testing. Eur Respir J 2020;55 (6):2000846.

7. Guérin C, Lévy P. Easier access to mechanical ventilation worldwide: an urgent need for low income countries, especially in face of the growing COVID-19 crisis. Eur Respir J 2020;55(6):2001271.

8. Truog RD, Mitchell C, Daley GQ. The toughest triage: allocating ventilators in a pandemic. N Engl J Med 2020;382(21):1973-1975. 


\section{Automatic Resuscitator For EMERgENCy Ventilation}

9. Schaller SJ, Altmann S, Unsworth A, Schneider G, Bogner-Flatz V, Paul T, et al. Continuous chest compressions with a simultaneous triggered ventilator in the Munich Emergency Medical Services: a case series. GMS Ger Med Sci 2019; 17:2-8.

10. Hu X, Ramadeen A, Laurent G, So PP-S, Baig E, Hare GMT, Dorian $P$. The effects of an automatic, low pressure and constant flow ventilation device versus manual ventilation during cardiovascular resuscitation in a porcine model of cardiac arrest. Resuscitation 2013;84(8): 1150-1155.

11. Marini JJ, Culver BH, Kirk W. Flow resistance of exhalation valves and positive end-expiratory pressure devices used in mechanical ventilation. J Crit Care 1987;2(3):222.

12. Ziehr DR, Alladina J, Petri CR, Maley JH, Moskowitz A, Medoff BD, et al. Respiratory pathophysiology of mechanically ventilated patients with COVID-19: a cohort study. Am J Respir Crit Care Med 2020;201 (12):1560-1563.

13. Mauri T, Spinelli E, Scotti E, Colussi G, Basile MC, Crotti S, et al. Potential for lung recruitment and ventilation-perfusion mismatch in patients with the acute respiratory distress syndrome from coronavirus disease. Crit Care Med 2020 2020;48(8):1129-1134.
14. Pan C, Chen L, Lu C, Zhang W, Xia J-A, Sklar M, et al. Lung recruitability in SARS-CoV-2 associated acute respiratory distress syndrome: a single-center, observational study. Am J Respir Crit Care Med 2020;201(10):1294-1297.

15. Yoshida T, Engelberts D, Otulakowski G, Katira B, Post M, Ferguson $\mathrm{ND}$, et al. Continuous negative abdominal pressure reduces ventilatorinduced lung injury in a porcine model. Anesthesiology 2018;129(1): 163-172.

16. The ARDS Definition Task Force. Acute respiratory distress syndrome: the Berlin definition. JAMA 2012;307(23).

17. Bachmann MC, Morais C, Bugedo G, Bruhn A, Morales A, Borges $\mathrm{JB}$, et al. Electrical impedance tomography in acute respiratory distress syndrome. Crit Care 2018;22(1):263.

18. Noordergraaf G, Dun PV, Kramer B, Schors MP, Hornman HP, de Jong W, Noordergraaf A. Can first responders achieve and maintain normocapnia when sequentially ventilating with a bag-valve device and two oxygen-driven resuscitators? A controlled clinical trial in 104 patients. Eur J Anaesthesiol 2004;21(5):367-372.

19. L'Her E, Roy A. Bench tests of simple, handy ventilators for pandemics: performance, autonomy, and ergonomy. Respir Care 2011;56(6): 751-760.

This article is approved for Continuing Respiratory Care Education credit. For information and to obtain your CRCE

(free to AARC members) visit 